\title{
Application of PBL Teaching Method in the Teaching of Medical Advanced Mathematics
}

\author{
Lang Liu \\ School of Information Engineering, Changsha Medical University, \\ Changsha City, Hunan Province, 410219, China
}

\begin{abstract}
PBL is short for Problem-Based Learning and it is a typical teaching method which takes students as the main body, and it is a hot issue that educators have been paying close attention to and studying in recent years. For medical students, the content of higher mathematics is often abstract and difficult to understand, so it is difficult to achieve the expected teaching effect by using the traditional teaching model. Based on the author's learning and teaching experience, this paper first analyzed the advantages of PBL teaching mode, and then analyzed the teaching difficulties of medical advanced mathematics, and finally put forward the perfect countermeasures of PBL teaching method that being used in medical higher mathematics teaching.

Key words: PBL; teaching method; medical advanced mathematics; perfect countermeasure
\end{abstract}

\section{Introduction}

As a basic course for most majors in medical education, the higher mathematics is not only an important foundation for students to follow the curriculum and learn in the future, but also an important way to cultivate students' scientific thinking, so higher mathematics is of great significance to the development of students. In 1969, Barrow, the American Academy of Neurology professor, first proposed curriculum model of problem-based Learning (short for PBL) in McMaster University in Canada[1]. In our country, PBL teaching model was first introduced by Shanghai Second Medical University and Xi'an Medical University in 1986. Since 1990, more and more universities have introduced PBL teaching 
model. Practice shows that in the process of cultivating creative, pioneering and practical talents, PBL teaching model has incomparable advantages of traditional teaching methods. At the same time, as a public compulsory course for medical students, medical advanced mathematics appears with its highly abstract features, the traditional teaching method is a teacher's book and a pen, and it translates and communicates the deep thinking in the brain with the aid of the language shell of thoughts[2]. This single teaching mode is incompatible with current quality education. Therefore, in order to meet the needs of developing medical education, make the teaching of higher mathematics keep up with the whole pace of medical education, effectively overcome the problems of single teaching model, old teaching contents, and formalist teaching methods and so on, it is imperative to reform medical higher mathematics teaching.

\section{Advantages of PBL teaching model}

\subsection{Teaching contents take problems as the core, which is conducive to realizing curriculum teaching goals}

In the PBL teaching model, the problem is the core of teaching contents. Teachers lead teaching by asking questions, and students acquire knowledge by solving problems. In the process of solving problems independently, students consolidate their understanding and grasp of basic knowledge, and their abilities of analyzing and solving problems have seen great progress. The PBL teaching model is helpful to stimulate the enthusiasm of students to learn higher mathematics, fully mobilize the initiative of students, and achieve the teaching goals of higher mathematics.

\subsection{Teaching activities take students as the main body, which is conducive to improving students' learning ability}

PBL teaching mode gives full play to students' main position in learning, it not only creates a relaxed, active learning atmosphere for students, but also allows students to fully express their views. This kind of active learning model not only lets students better understand and master the "Three Basics", but also enables students to improve their various abilities, for example: the ability to search literature documentation, the ability to summarize and analyze reasons, the ability of communication, the ability to research deeply, and the ability to learn independently and so on[3].

\subsection{Emphasizing cooperation and communication is conducive to cultivate students' sense of team}

In the process of introducing PBL teaching mode, learning and cooperation in groups is a very important part. In each group, each student takes the initiative to participate in group activities, they communicate with and learn from each other 
and work together to solve problems. This kind of teaching mode not only increases students' learning interests, but also improves their abilities of communication and cooperation, which is beneficial to promote the formation of students' team spirits.

\section{Teaching difficulties of Medical Advanced Mathematics}

\subsection{Teaching contents are short of entertainment and practicability}

Mathematics uses its perfect axiomatic system to show the infinite charm of human thinking. Meanwhile, it is also gradually away from the general public because of its high abstraction and strict logical reasoning. At present, when people enjoy the wide information technology, they often ignore the mathematics behind these techniques, and can not realize the indispensability of modern mathematics in it. Because of being overlooked the important role, mathematics can not be interesting. Especially in medical colleges, there is a gap between students' strong medical professional consciousness and the pure theory of higher mathematics. Most existing medical textbooks of higher mathematics describe the basic theoretical framework of calculus, students generally feel that they learn mathematics automatically, the basic system of definition-theorem-inferenceexercises also makes the higher mathematics boring. As a result, this course is generally ignored, and it is hard for teachers to organize teaching. The students' learning initiative is low, and the learning effect is limited. Taking the fourth edition of 'Medical Advanced Mathematics' for example, the book adds a number of medical applications, but these contents are only exercises and can not meet students' needs to combine theory with practice. On the other hand, modern mathematics has a wide range of applications and is closely related to computer science and technology[4]. It is also a long history of mathematics being used in the field of medicine, such as epidemic model research, diagnostic medical statistics and so on. Therefore, to fully show the usefulness of mathematical tools, it is necessary to adjust the teaching contents of medical advanced mathematics and strengthen the contact with medical courses.

\subsection{Teaching methods are mainly based on theory and lack of experimental operation}

We emphasize that the medical colleges should cultivate a group of high quality talents who can meet the needs of different posts and concentrate on cultivating students' practical abilities. Therefore, according to the main course of medical science, some medical colleges begin to integrate teaching contents, compress theory class hours, and increase the proportion of experimental classes to highlight the abilities of medical students. However, in the course of mathematics teaching, which is the most important research tool in natural science, all classes are taught in the form of theory, and students have no chances to practice personally, so the two are contradictory. In order to make mathematics course 
teaching match the goal of personnel training in medical colleges, it is necessary to reform the current teaching environment and teaching model. Teachers should encourage students to practice by themselves and let them solve practical problems with the help of their familiar, favorite computers, make students experience the process of solving practical problems by using mathematical knowledge. In the process of cultivating students' abilities to solve problems independently, further stimulating their desire to learn mathematics[5].

\subsection{The design of teaching method does not consider the connection with the following courses}

The following courses of medical advanced mathematics include medical statistics, mathematical modeling and so on. First, these courses do not have successive opening time. Most colleges set up higher mathematics in the first semester of the freshman year, and set up medical statistics or mathematical model in the junior year. Two courses are linked, but the interval is too long. Many students hardly read math books after completing credits, and they can not remember the knowledge they have learned when the higher mathematics knowledge is needed in mathematical modeling[6]. On the other hand, the teaching results are not inheritable. Higher mathematics strengthens students' abilities by doing exercises, and it rarely involves creative mathematical tools, however, mathematical modeling and medical statistics have strong application backgrounds, and they require students to have certain abilities of creative thinking. This will fall into a vicious circle: students complain that it is useless to learn advanced mathematics, or do not know how to use it, however, when it needs to use mathematical model to solve practical problems, they feel that they do not a have mathematical basis.

Based on the current teaching environment of higher medical mathematics, it is imperative to reform the teaching methods. The teaching of higher mathematics should be guided by the constructivism teaching theory, and emphasize that the teaching should take the student as the center. The subject of learning (learners) reselect, process and handle external information according to their existing knowledge and experience, and actively understand and construct new knowledge and information. PBL curriculum model can be a good reflection of this teaching concept.

\section{Perfect countermeasures of PBL teaching method in the teaching of Medical Advanced Mathematics}

\subsection{Change teachers' teaching concepts, and improve their abilities of using PBL teaching method}

The operation mode of PBL teaching consists five parts, which are asking questions, establishing hypotheses, collecting data, proving hypothesis and summarizing. PBL teaching method is based on the discussion of students and 
puts the whole learning process into a meaningful problem situation. It is different from the traditional teaching methods, to adapt to this kind of teaching method and achieve a better teaching effect, teachers should change their original traditional concepts. In the teaching activities, teachers should not only teach knowledge, but also guide and encourage students to find effective learning methods. Teachers and students are partners, and they need to cooperate with each other in the learning. Teachers should combine the teaching objectives to assess students' overall cognitive level and propose questions of moderate difficulty. Students investigate, analyze and solve this problem. Teachers should properly guide students, timely assess the degree of their mastery of knowledge points, the learning abilities of the individual and the group, give students timely encouragement, agree their learning outcomes, listen to the views of students, and believe students' abilities. In the time of encouraging students and improving their learning enthusiasm and confidence, teachers should not intervene students. Transitional interference will limit the students' thoughts and ideas, and limit their creativity. Therefore, in order to enhance the teaching abilities of PBL, the teacher should set up his own position and change the concept of teaching.

\subsection{Combined with the traditional teaching methods, and strengthen the pertinence of PBL teaching method}

The traditional teaching mode is deeply rooted in the educational history of China for thousands of years. Teachers carry out education and teaching activities in a planned and systematic way at the instance of the teaching syllabus, so the whole teaching process is teacher speaking on the stage and students listening below, the teachers' behavior will have an impact on their future learning and work. The knowledge structure in higher mathematics is systematic, so it is easier for students to acquire the solid theoretical knowledge by using the traditional teaching method. However, there are many shortcomings in the traditional educational mode. The whole process of traditional teaching is concentrated on teachers, and it is difficult to stimulate the students' interests in learning in addition, the teaching content is limited by the syllabus, and the cultivation of students' comprehensive ability is neglected. Because the two kinds of teaching modes have their own advantages and disadvantages and can not replace each other, we should combine the PBL teaching method with traditional teaching method in the higher mathematics teaching, and let the students and teachers both learn something in the teaching activities. First of all, teachers should help students to build a basic knowledge framework. Then, with the gradual accumulation of knowledge, teachers can apply the PBL teaching method into the basic skills module, let students find relevant information to solve problems through reasoning and analysis, enhance their mathematics ability and cultivate students' ability of comprehensively using existing knowledge. During the whole teaching process, applying the basic knowledge of some knowledge points into the teaching of PBL can make the teaching part be more targeted. 


\subsection{Reform the teaching evaluation model, and guide the PBL teaching method to carry out}

Teaching evaluation system is an important guarantee to ensure the PBL teaching method to achieve the expectation and teaching purposes. In order to guide the development of PBL teaching method, it is necessary to establish a teaching evaluation feedback system which is suitable for PBL teaching method. For a long time, the assessment model of higher mathematics for students' achievements has been written examination, the examination form can not inspect the degree of students' understanding and mastery of knowledge, but combat students' enthusiasm to think actively. The traditional evaluation method especially not suits PBL teaching mode[7]. Whether the student achievement assessment method of PBL is scientific and reasonable will directly affects the teaching effects and the development of PBL teaching method, so establishing a fair, reasonable, and scientific performance appraisal system is particularly important. In PBL mode, the final total score of students includes two parts, one part is end results. It adopts the written examination form, and accounts for $60 \%$ of the total score. The examination includes the basic part and extended part. The other part is the usual results, and it accounts for $40 \%$ of the total score. The usual result evaluates students' performances in the whole teaching process and the performances includes their initiative, enthusiasm, the ability to analyze problems, the ability to solve problems, the ability to cooperate with others, and the sense of teamwork. At the same time, teachers should make an effective adjustment according to students' evaluation and the feedback appeared in the teaching process, which will further improve the quality of teaching, benefit teachers as well as students and guide the further development of PBL teaching method.

\section{Conclusion}

The introduction of PBL teaching mode in higher mathematics teaching can not only stimulate students' learning enthusiasm, but also develop their logical thinking, and improve their abilities to analyze, study, and deal with practical problems. The application of this teaching model in the advanced mathematics is beneficial to the realization of the teaching objectives, the improvement of students' learning ability and the cultivation of students' team consciousness. In the teaching practices, we should start from the actual situation, combine the PBL teaching mode with the corresponding teaching methods, actively explore and innovate, and truly improve the students' mathematical literacy. 


\section{References}

[1] Luo Qun, Zhao Ping, Yang Wanjun, he Yan. Analysis and research of PBL teaching method in Higher Mathematics. Science and Technology of China, 20, pp.68-69, 2009.

[2] Chen Hao, Zheng Shanting. Study on the implementation of PBL teaching method in the teaching of Undergraduate Tourism Management. Education and Teaching Research, 12, pp.100-103, 2010.

[3] Yang Lijun, Wang Bao DUI. Exploration of PBL teaching method in rural junior high school mathematics. Journal of Aba Teachers College, 03, pp.126-128, 2013.

[4] Hao Yanqin. PBL teaching method in the teaching of pharmaceutical analysis theory. Journal of Clinical Rational Use of Drugs, 04, pp.177-178, 2015.

[5] Zhou Jianhua. The application of PBL teaching model in the teaching of advanced mathematics. Journal of Tongren University, 04, pp.185-187, 2015.

[6] Xia Yong, Li Yi, Liu Shimin, Shen Yong, he. PBL model: the only way for the reform of clinical teaching of acupuncture and moxibustion. Journal of Chengdu University of Traditional Chinese Medicine (EDUCATION SCIENCE EDITION), 04, pp.4-6, 2011.

[7] $\mathrm{Yu} \mathrm{Xu}$ you. PBL teaching method in the application of econometrics. Era of Economic and Trade, 09, pp.68-70, 2016. 